\title{
Ecological Principles for the Establishment and Management of National Parks and Equivalent Reserves*
}

\author{
by \\ NICHOLAS POLUNIN \\ President of the Foundation for Environmental Conservation; Secretary-General and Editor of the International Conferences \\ on Environmental Future; Founder and Editor of Environmental Conservation; Convener and Editor of Environmental \\ Monographs and Symposia, 15 Chemin F.-Lehmann, 1218 Grand-Saconnex, Geneva, Switzerland.
}

$\&$

HAROLD K. EIDSVIK

\begin{abstract}
Executive Officer, IUCN Commission on National Parks and Protected Areas, International Union for Conservation of Nature and Natural Resources, 1110 Morges, Switzerland; formerly Deputy Chairman, IUCN Commission on National Parks and Protected Areas and Senior Policy Adviser to Parks Canada.
\end{abstract}

\section{INTRODUCTION}

The idea of setting aside representative areas of unspoiled country for quiet enjoyment and detailed study of natural phenomena can scarcely have failed to come to some of the far-sighted naturalists and others among our forefathers - at least in the days of Malthus or among those who had followed his writings about the dangers of human over-population. Consequently it seems unlikely to be mere coincidence that the earliest printed use, in an English-language text, of the name of our key science of ecology ${ }^{\dagger}$, almost coincided in time with the first practical expression of the movement to establish national parks and nature reserves for scientific study and preservation in perpetuity. Yellowstone, the world's first real National Park according to our modern ideas and criteria, was established by act of the United States Congress in 1872, and it would seem an unlikely coincidence if its founders had not heard of the embryonic science of ecology which must have been talked about at that time at least in Germany where Haeckel lived and taught. In any case, it seems that ecology and National Parks were practically born together and should remain in intimate association to the end of time.

The central role of ecology in park planning and management is now so widely recognized that it is practically unthinkable that any nature reserve, let alone a major park, should be established without due regard being paid to ecological principles and the local situation. But although what are widely referred to as 'National Parks

\footnotetext{
* Substance of paper presented by the first-named Author at the Twentieth Anniversary celebrations of the Friends of the Argentina National Parks at Hotel Mitre, Buenos Aires, 6-10 November 1978.

†According to the Oxford English Dictionary, this was by Ernst Heinrich Haeckel in 1873 in its antique form of 'oecology', although according to E. C. Odum (Fundamentals of Ecology, Edn 1, p. 3, 1953) it was first used by Haeckel in 1869 (or apparently in 'Natural History of Creation, 1868' according to World Who's Who in Science from Antiquity to the Present, 1968).
}

and Equivalent Reserves' increasingly serve the needs of ecologists, there is still a considerable lack of harmony among the latter as to what should be done, and where and when, to establish and maintain a suitable network of such protected areas in different parts of the world. These difficulties are compounded and even magnified many times by the frequent need to operate with a fully interdisciplinary team including sociologists and economists as well as ecologists.

We have often thought how remarkably simple in themselves, yet complicated in outcome, are many of the best ideas. And so it is with ecology. What could be simpler than the realization that every organism - be it big or small, plant or animal or microbial - has its particular environment, or surroundings, in which it lives and ultimately dies! Yet the full study of that environment is apt to be more complicated than the study of the organism itself - even if the latter be Man, as in many ways the highest and most complex form of life. This study of living organisms (including Man) in relation to their environment (including one-another) is the very essence of ecology, of which the principles are fundamental for the proper establishment and maintenance of National Parks and Nature Reserves.

\section{ECOLOGICAL PRINCIPLES APPLYING TO CHOICE OF SITE AND INITIAL ESTABLISHMENT}

The leading criterion to be considered in choosing a site for preservation as a National Park or Nature Reserve is the special (preferably unique) natural quality that is contained within its boundaries. This more or less unique natural quality may be expressed through a great diversity of species, or by vast numbers of a particular species or, on the contrary, by a few representatives of an endangered species. On the other hand, the area may be characterized by a unique geological feature, landform, or marine environment. Uniqueness is the quality that distinguishes a particular area as warranting the protection 
which can be afforded by a special legal designation. Given the option, one would generally give preference to an area with great diversity rather than lesser diversity. When once the natural qualities of an area have been identified, one must thoroughly evaluate the complex social, economic, and political, aspects that will in turn determine whether it can be effectively protected for posterity and indeed in perpetuity.

In all of these and many other connections, ecological principles clearly apply. Thus it is important to maintain and broaden public interest and education to increase appreciation of 'natural history' and the significance of conservation, for which the attraction of variety and change (including decay) can be of great help. It is also necessary - having set aside an area of sufficient size to be ecologically viable according to the latest criteria (e.g. Miller, 1978) - to be able to segregate and protect it not only from undue public interference (such as the building of hotels and highways) but also from disturbance by, for example, inwandering herbivores. For such purposes an adequate buffer-zone can be crucial. As for financing for suitable management, the budgeting must be done to implement plans laid down with full ecological knowledge and foresight, and suitably qualified and dedicated personnel should be appointed under adequately generous terms and conditions.

Ecological principles and concepts are so central to the conservation theme and process that - as in the case of natural areas in the manner already presaged-it is reassuring to think that they probably evolved substantially together. But, probably unfortunately, much of today's conservation effort continues to be based on taxonomic categories of individual plant or animal taxa - with only minimal focus on communities, on processes, and on proper integration of the data into environmental models or practical actualities. Although considerations of ecosystems are coming more and more into vogue*, according to Dansereau (1966) 'we have been slow to realize that ecology is not a purely biological science, since it must account for the whole environment and trace the origin and effect of the resources which the plant and animal bodies are instrumental in cycling'.

A general ecological principle to be constantly borne in mind is that of the intricate interconnectedness of living things and their environments, and how some action, even of initial establishment of a park or reserve, will inevitably affect the local situation and in due course probably others lying farther afield. This interdependence seems inherent in Haeckel's assertion of the essential unity of organic and inorganic Nature - a concept which he may in turn have borrowed from Darwin, whose first German advocate he appears to have been. Another such general ecological principle is that of continual change where life is concerned-including succession of plants and to some extent also of animals, which must always

*Here it may be of interest to note that one of us (N.P.) was A. G. Tansley's only research student at Oxford in the early 1930s when he was deliberating on the concept of the ecosystem which, following his introduction of it in 1935, has now become about the most-used term in all ecology. be borne in mind as changing local ecosystems and other situations in a usually predictable direction. It is this inherent process of change in Nature that signals the need for Man sometimes to intervene in the natural processes to ensure that the initial objectives of the park or reserve, such as the preservation of particular species, are assured. As knowledge of natural processes increases, the opportunity for skilled management increases. It is now only rarely that conservation objectives can be attained by non-involvement or non-management.

Yet another major principle of ecology is that chemical substances in ecosystems commonly cycle through and among the components of such systems, and often do so at different speeds. Consequently, in the words of Willard (in press), "they are available for reuse again after time-periods which depend upon their paths of cycling and means of disposal'. On the other hand, energy follows a one-way downhill path of dissipation.

Another great principle of ecology, which should be actively remembered in the establishment of national parks and reserves, is that the surface of the Earth is occupied by a vast array of ecosystems, both large and small, which interact chronically with their neighbours. Within these ecosystems, each type of organism has a role to play, being significant in the total functioning of the system. The ultimate expression of all ecosystems in the world as a whole is as components of the biosphere, and maintaining a diverse system of parks and reserves will help to ensure the preservation of diverse ecosystems and species and hence of integral parts of the biosphere.

Another pertinent principle is that of limiting factors: 'Within all ecosystems, specific features of the environment interact with the genetically-controlled capabilities of living organisms. These interactions define the operating parameters or behavioural characteristics of that ecosystem and of the living organisms within it' (Willard, in press). For this reason, in establishing the boundaries or parameters of protected areas with specific protection objectives, the ideal must always be the incorporation of topographically discrete ecosystems. The effectiveness of the protected area is greatly reduced if species which are to be protected spend portions of their life-cycle outside the boundary of the protected area. In the same vein, management problems are greatly magnified by inappropriate boundaries. Nonetheless, when dealing with migratory species and large mammals, it is difficult if not impossible to reach the ideal.

We should also bear in mind the prolific nature of biological reproduction, and how the vast majority of taxa of living organisms have the capacity to produce far more of their kind than can possibly be supported by the ecosystem in which their antecedents lived. The evolutionary reasons for this probably stem from the fact that over-population can improve the chances of some individuals surviving all the exigencies of life to carry on the line. This brings us to considerations of carryingcapacity - the capability to sustain a given amount of life without collapse, or to uphold an optimum level of production. If we humans go on breeding in such a 'population swarming' as is now being indulged in, we shall risk 
ultimate collapse or, as the Editor of The Ecologist warns us repeatedly, we shall 'all starve to death'. So particular areas, especially of human interference, should not be allowed to become over-populated by particular species. In ecosystem development, 'natural' successional and other processes should probably be allowed where suitable to continue undisturbed or, if necessary, be encouraged. Moreover, natural processes often exist for healing natural ecosystem disruptions-such as those caused by landslides, fire, or insect infestations.

Recognizing that systems commonly have thresholds which, when surpassed, will result in the breakdown of the system, the concept of carrying capacity is being applied very widely in the management of parks and reserves. Managers are concerned with the capacity of natural systems as well as social systems, and principles of island biogeography may apply also to limit restocking possibilities on land.

Finally, we must express the gravest concern that, in both the over- and under-developed worlds, established parks and reserves are under constant threats-either from affluent societies placing excessive recreational pressures on these areas, or from indigenous people invading protected areas to sustain their limited income and food sources. Unless protected areas can be integrated with the overall governmental objectives for human welfare, even the 'islands' which are now protected will be widely ravaged before the turn of this century.

\section{DETERMINING AND MANAGING PARKS RESOURCES}

Having chosen the site of our park and delimited its area according to the above ecological principles and other considerations, we must now explore it in detail, prepare an accounting of its resources, and monitor their uses and any progression-not forgetting possibilities of retrogression which will need to be tackled. Here we should remember that the role of the ecologist in the management of a protected area must be considered from several different perspectives. Thus he may be called on to provide 'a scientific opinion', or he may be called on to assist in the planning and management of areas and to monitor the changing environment 'to determine whether management is having the desired effect: for instance, if an early burning programme or an elephant reduction scheme is resulting in the improvement of certain woody habitats' (Grimsdell, 1977).

Guided often by a love of Nature, there have been many thousands of people dedicating their lives to one or another aspect of conservation-particularly in recent years. Some of these have dealt with the conservation of animals as their central concern, others have treated the conservation of plants as their central concern, and others again have seen the preservation of Man as their leading concern. Yet, somehow, all of these forces have converged on the concept of 'national parks and protected areas', or on some such theme as pollution abatement, as a central means of achieving their diversified objectives in the preservation of ecosystems.
When both industrial pressures and population pressures were low, conflicts between Man and Nature were rare. But as human populations grew and the demands for natural resources expanded, the conflicts between preservation for Man and preservation for Nature also grew. Competition for relatively scarce resources became a watch-word in all continents and countries, and we entered the present period of environmental awareness (Polunin, 1978). In a world of unknown but presumed abundance, there had been little concern about exploitation or even about environment per se; people lived, literally, in ignorance of such concepts as 'ecological balance' - the maintenance of all species in harmony with the systems in which they existed. But now the situation has changed drastically, with serious disharmony all-tooevident and even killings seen quite widely - witness the chronic and large-scale fighting in Beirut. To what extent this 'Beirut Syndrome'* may be due to territoriality we simply do not know; but we should remark that overpopulation cannot be indulged in with lasting impunity.

\section{CONSERVATION STRATEGY}

A World Conservation Strategy that is being drafted by IUCN and other bodies, emphasizes the need for an inventory of natural resources as a fundamental base for world conservation action. This is at present still under preparation but, according to Curry-Lindahl (1978), 'a necessary first step of such a strategy must be a global campaign for conservation education as a basis for environmental understanding at all social levels and ageclasses'.

The current situation vis-à-vis allocation of all-tooscarce conservation funds is somewhat akin to awaiting the prize in a national lottery; some will become wellendowed but the vast majority will continue to suffer! Even the selection of priority areas of interest poses complex questions in relation to these scarce funds. Concentration areas or themes have been selected: moist tropical forests, 'the seas must live', 'the tiger', 'the elephant', etc. But how many areas or species have similar needs? How much should be spent on protecting the Whooping Crane or the Blue Whale, for instance? Needless to say, decisions must be taken in the light of current knowledge.

The fundamental question of resource inventories must be approached on a global basis as well as on regional and area bases. Both comparability and compatibility of the data at each of these levels are essential, and their elaboration constitutes another of the complex tasks which must be accomplished. Moving from the general or horizontal to the specific or vertical, we must constantly improve the data-base, so that we develop a capability not only to know and say what we have, but also to detect processes and change.

On a global basis, IUCN's Commission on National Parks and Protected Areas (CNPPA) is developing a mon-

\footnotetext{
*Having been asked about the origin of this term (though the connotation is tragically obvious), we have to admit that we think it was first used as the title of a brief editorial in Environmental Conservation (Vol. 3, No. 1, p. 2, Spring 1976).
} 


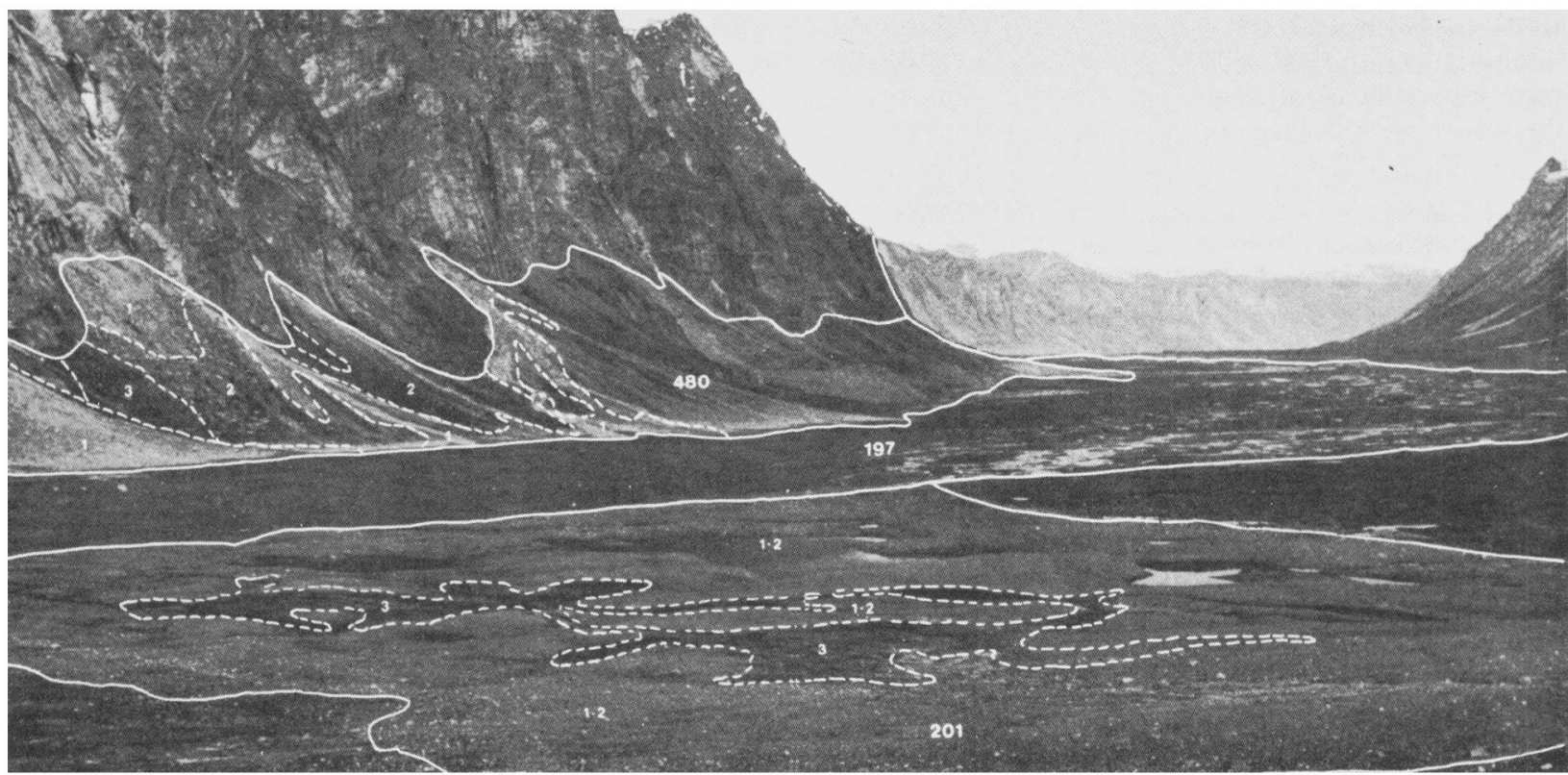

Fig. 1. Biophysical land-classification divides the natural park or other area into relatively homogeneous landscape units on the basis of soils of different types and/or origins, of any additional surface deposits, of landforms, and of vegetation-types. Auyuittuq National Park, Parks Canada photo.

itoring system based on biogeographical concepts evolving from the compilations of Dasmann $(1972,1973)$ and IUCN (1974). The first-level inventory concerns itself with the identification of all protected areas in each of the biogeographical provinces. A network of monitors or correspondents is being established to provide basic data on each protected area (Table I). These data are being published in directories similar to the ' 1975 United Nations List of National Parks and Equivalent Reserves' (IUCN, 1975a) and the loose-leaf 'World Directory of National Parks and Other Protected Areas' (IUCN, $1975 b$ ).

The refinement of the first-level, basic inventory in a second stage of the monitoring process will provide further data on endangered and threatened species within these areas. It will also provide a status report on the effective management of these areas in relation to predefined criteria and objectives. One objective of the inventory is to provide more effective mechanisms for defining financial priorities for conservation projects. In addition to providing aid towards financial decisions, the inventory will assist in defining priority areas in need of concerted conservation action. The Directory will also be available as a basic source-book related to the World Conservation Strategy.

Moving from the global to the local or 'area' level, the need for basic inventories remains fundamental. In-depth knowledge of the resources of all protected areas is basic to master-planning and effective management. 'A distinguishing feature of national park resource inventories is that, while they must concentrate on the present state of the resources, attention must be given to their past and anticipated future conditions. Because of the special pur- pose [for which] national park land is set aside, the complex process of biological change must be thoroughly known to the absolute extent that is practicable' (Desmeules, 1976). Particularly useful in documenting such knowledge can be a biophysical land-classification, subdividing the area into relatively homogeneous landscape units on the basis of soils of different types and/or origins, any additional surface deposits, landforms, and vegetation-types, as illustrated in Fig. 1. At the same time the potential uses to which the land could be put, as illustrated in Fig. 2, should be borne in mind for various reasons.

Important here as in all our work should be the full incorporation of Man as an ecosystem component.

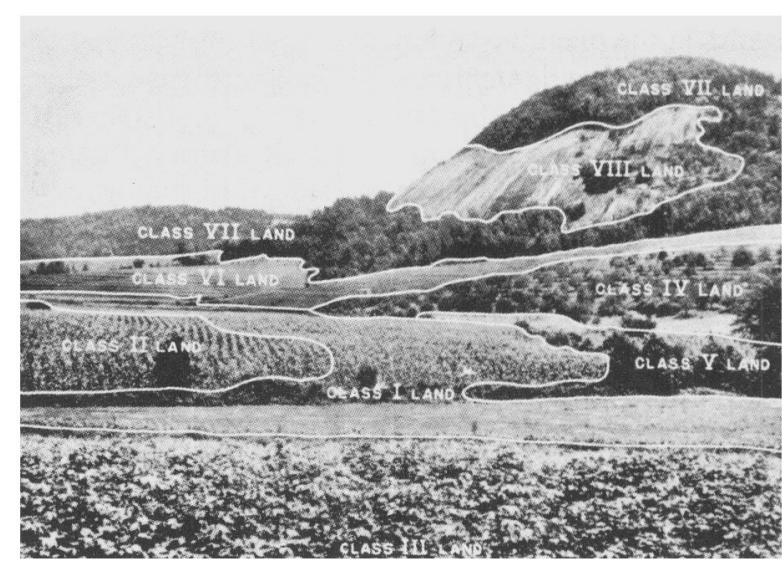

Fig. 2. Shows examples of the eight main land-use capability classes (from Polunin, N.: Introduction to Plant Geography and some Related Sciences, p. 560, 1960, by courtesy of U.S. Soil Conservation Service). 
TABLE I. Proposed Basic Data-sheet for Parks and Equivalent Areas.

(1) IDENTIFICATION

(i) Name and CNPPA type of area

(i.e., strict nature sanctuary, National Park, Provincial Park, private sanctuary)

(ii) Designated Biosphere Reserve

Yes.... No.... Date established...

(iii) Designated World Heritage Site Yes.... No.... Date established....

(2) GEOGRAPHICAL LOCATION

Latitude.... Longitude.... Biogeographic Province....

(3) ALTITUDE

(a map of a suitable scale if possible)

(4) SIZE OF AREA Hectares.... (total area)

Further details on area should be provided if available

(5) LEGAL STATUS

Legislation.... decree.... proclamation.... Date establ... Government: Central Local

Provincial Private

(6) PHYSICAL FEATURES

(7) LIST SPECIES PROTECTED (flora and fauna)
(i) abundant (iii) threatened

(ii) rare (iv) endangered

(8) FORECAST OF PROTECTIVE STATUS (disturbances, deficiencies in to the future)

(i) stable (i.e., expected to provide effective protection)

(ii) threatened (potential for logging, agriculture)

(iii) in danger (e.g. hydroelectric development will inundate area)

(9) TOURISM

(10) PRINCIPAL REFERENCE MATERIALS (list)

(11) STAFF

(12) BUDGET

(13) LOCAL PARK ADMINISTRATION

(14) RECOMMENDED ACTION

The breadth of the inventory must encompass the following:

PHYSICAL COMPONENTS

Climate

Ecological and geomorphological aspects: bedrock superficial deposits soil landforms

Water

drainage basins

volume and flow

physical characteristics

chemical

biological

phenomena: hot springs, geysers, glaciers, etc.

BIOTIC COMPONENTS

Plant life

phy tosociological characteristics

tolerance of communities

long-range stability

rare and endemic plants

Animal wildlife

species

distribution and movements

behavioural traits

Man*

rare and endangered considerations

anthropology economics

history political aspects

sociology

*Important here as in all our work should be the full incorporation of Man as an ecosystem component.
Central to the inventory compilation is the integration and synthesis of the data, so that processes and preservation values can be effectively considered in protectedarea management plans. 'Certainly, if we are to interpret and to detect behaviour and function, we cannot do so in the absence of thorough inventories and adequate descriptions' (Dansereau, 1966).

One of the results of the General Assembly of 1 UUCN in 1975 (in Zaire) was their shift in conservation philosophy away from national parks and reserves as a sole mechanism for achieving protected status for areas and species. A broad range in types of conservation areas was seen as a fundamental mechanism for resolving conservation problems in a world that is characterized by great natural and political diversity. At the General Assembly in 1978 (at Ashkhabad, USSR), appropriate groups and categories were presented as a future mechanism for achieving protective status (Table II).

Five phases may be recognized in conservation as a social discipline: legislative, biological, ecological, sociological, and engineering or management (cf. Dansereau, 1966). There is little doubt that we have made substantial progress in the first three of these phases and that we have embarked on the fifth, 'engineering'. But the situation with regard to the fourth, the sociological phase, remains doubtful. Management (engineering) has taken over, or is in the process of taking over, from ecological and allied ('don't touch') preservation as the primary means of achieving conservation objectives.

This shift in the practical approach to our goal is in itself a remarkable though necessary one. When such an approach can be fully integrated with social and economic considerations, the ecologist's role in managing protected areas will ensure that his broader perspective of 'Man and Nature' will be further projected into resource-winning and industrial practices, yielding a 'Man in Nature' strategy or at least ethic. No longer will the world require national parks and protected areas as islands of conservation in a sea of abuse. The protection of all species will be integrated. But national parks and other protected areas will always be needed for research and recreation, and, as time goes on, should become more and more interesting to an increasingly enlightened public.

TABLE II. Categories of Conservation Areas.

\begin{tabular}{|c|c|}
\hline \multicolumn{2}{|l|}{0} \\
\hline Category I & Scientific Reserve/Strict Nature Reserve \\
\hline Category II & National Park/Equivalent Reserve \\
\hline Category III & Natural Monument/National Landmark \\
\hline Category IV & $\begin{array}{l}\text { Nature Conservation Reserve/Managed Na- } \\
\text { ture Reserve/Wildlife Sanctuary }\end{array}$ \\
\hline Category V & Cultural Landscape/Heritage Landscape \\
\hline GROUP B & \\
\hline Category VI & Resource Reserve \\
\hline Category VII & Natural Biotic Area/Anthropological Reserve \\
\hline Category VIII & $\begin{array}{l}\text { Multiple-use Management Area/Managed- } \\
\text { resource Area }\end{array}$ \\
\hline
\end{tabular}

GROUP C

Biosphere Reserve World Heritage Site (Natural) 


\section{SUMMARY}

The central role of ecology in park planning and management is now so well recognized that the establishment of park programmes without ecological advice seems un. thinkable. Yet attempts to link ecological principles and planning principles are still fraught with difficulty. Communications between interdisciplinary teams are complex.

The Authors of this paper illustrate how the principles of ecology and the practices of park management are interconnected and interdependent. The need for resource inventories as a foundation of park management is explored and emphasized as essential, as is the need for constant monitoring to ensure that conservation goals are attained. Underlying the article are basic convictions that dynamic ecosystems require dynamic management, and that management in the future will be required increasingly to attain specific conservation objectives.

\section{REFERENCES}

CURRY-LINDAHL, K. (1978). Background and development of international conservation organizations and their role in the future. Environmental Conservation, 5(3), pp. 163-9.

DANSEREAU, P. (1966). Ecological impact and human ecology. Pp. 425-60 in Future Environments of North America (Ed. F. Fraser Darling \& John P. Milton). Natural History Press, Garden City, New York, N.Y.: xv + 767 pp.
DASMANN, R. F. (1972). Towards a system for classifying natural regions of the world and their representation by national parks and reserves. Biol. Cons., 4(4), pp. 247-55.

DASMANN, R. F. (1973). Classification and Use of Protected Natural and Cultural Areas. IUCN Occasional Paper No. 4, 24 pp., mimeogr.

DESMEULES, P. (1976). The resource information base for Planning. Parks, 1(3), pp. 4-7, 3 figs.

GRIMSDELL, J. (1977). The ecological survey. Parks, 2 (2), pp. $1-4,3$ figs.

HAECKEL, E. H. (1873). Natural History of Creation. [Not available for checking.]

IUCN (1974). Biotic Provinces of the World: Further Development of a System for Defining and Classifying Natural Regions for Purposes of Conservation. IUCN Occasional Paper No. 9, 57 pp., mimeogr., 7 sketch-maps.

IUCN (1975a). 1975 United Nations List of National Parks and Equivalent Reserves. IUCN Publication New Series No. 33, $84 \mathrm{pp}$.

IUCN (1975b). World Directory of National Parks and Other Protected Areas. International Union for Conservation of Nature and Natural Resources, 1110 Morges, Switzerland: Loose-leaf, with occasional sketch-maps, etc.

MILLER, R. I. (1978). Applying island biogeographic theory to an East African Reserve. Environmental Conservation, 5(3), pp. $191-5,3$ figs.

POLUNIN, N. (as N.P.) (1978). (Editorial) Man's increasing awareness of his environment. Environmental Conservation, $5(3)$, pp. $161-2$

WILLARD, Hon. B. E. (in press). Ethics of biospheral survival: a dialogue, Part I. Pp. 506-22, in Growth Without Ecodisasters? (Ed. Nicholas Polunin). Macmillan, London \& Basingstoke, and Halsted-Wiley, New York.

\section{Factors Influencing Urban Design: A Systems Approach}

Following their successful 'NATO Advanced Study Institute' last year on 'Water Resources and Land-use Planning' (cf. Environmental Conservation, Vol. 5, No. 1, p. 20, Spring 1978), the Université Catholique de Louvain, Louvain-la-Neuve, Belgium, will be holding another such major workshop during 2-13 July of this year on the above topic. The course will analyse the interrelationship between environmental concern and energy-saving in the planning of urban development, and will maintain an awareness of energy problems as the 'guiding link' in a fully multidisciplinary approach. The objective of the course will be to provide a forum for an exchange of knowledge and varying experience which will have a beneficial effect through allowing research workers and specialists from different fields and countries to meet and exchange information.

The following is the provisional lecture programme: (1) Planning and Engineering Factors-'Assessment of Energy Consumption of the Urban Forms', by L. Bolle; 'Criteria for Assessing Human Well-being in Urban Settlements', by G. Epstein; and 'Density, Energy Consumption, and Physical Layout', by P. Laconte, Director; (2) Architectural Factors - Architecture and Urban Form', by A. Rapoport; 'Time and Patterns in Urban Design', by C. Alexander; and 'Planning and Architectural Models', by F. Choay; (3) Economic and Sociological
Factors - Political and Administrative Factors of Urban Design', by E. Wertz; 'Economics of Urban Design - Recent Cases in the USA', by J. Rouse; (4) Systems Approach - Factors Influencing Urban Design: Systems and Models', by J. E. Gibson (Co-Director); 'A Multi-media Approach to Decision-making in Urban Design', by A. Jones; and 'The City as an Open-ended System', by P. M. Allen.

As previously, the number of participants will have to be limited. There is no tuition fee, but participants will be required to pay BF. 10,000 (about US $\$ 334$ ) to cover the costs of lodging, reprints, and social activities. Accommodation will be available in the University town for the duration of the course. Grants will be available on a selective basis to cover these costs and also travel expenses of some participants. Requests concerning grants, and for any further information that may be required, should be sent to the undersigned with as little delay as possible. 